\title{
What are the benefits of endoscopic ultrasound in the staging of pancreatic cancer?
}

\section{QuAIS OS BEnEFícIOS DA ECOENDOSCOPIA NO ESTADIAMENTO DO CÂNCER DE PÂNCREAS?}

Sílvia Mansur Reimão ${ }^{1}$, Jarbas Faraco Maldonado Loureiro ${ }^{1}$, Rogério Colaiacovo ${ }^{1}$, Ricardo Ganc ${ }^{1}$, Elias Jirjoss Ilias ${ }^{2}$, Lucıo Giovannı Batısta RossinI ${ }^{1}$

${ }^{1}$ Endoscopists, Centro Francobrasileiro de Ecoendoscopia, School of Medical Sciences of Santa Casa Misericórdia de São Paulo, São Paulo, SP, Brazil 2PhD-Professor at the Surgery Department of Brotherhood of Santa Casa de Misericórdia de São Paulo, São Paulo, Brazil

\section{Case report}

Female patient, 73 years old, with a history of jaundice, epigastric pain radiating to the back, and weight loss of $15 \mathrm{~kg}$ in three months. She was referred to our hospital with a possible diagnosis of cancer in the head of the pancreas, with evidence of increased pancreatic head and dilatation of intra- and extra-hepatic biliary ducts on abdominal computed tomography and magnetic resonance cholangiography. Due to obstructive jaundice, a retrograde cholangiopancreatography was performed, showing partial stenosis of the distal common bile duct with dilatation of bile ducts, which was drained by inserting two biliary plastic stents. An endoscopic ultrasound was requested to further study the pancreas and adjacent structures.

During the investigation, a hypoechoic heterogeneous lesion measuring $35 \times 30 \mathrm{~mm}$ and presenting ill-defined margins was seen in the pancreatic head. There were also signs of vascular involvement, with loss of acoustic interface with the wall of the portal vein and absence of vascular flow (thrombosis). Furthermore, dilatation of the main pancreatic duct $(6 \mathrm{~mm})$ in the regions of body and tail of the pancreas upstream to the lesion described above was observed. Echo-guided punctures were performed in the lesion for histological clarification.

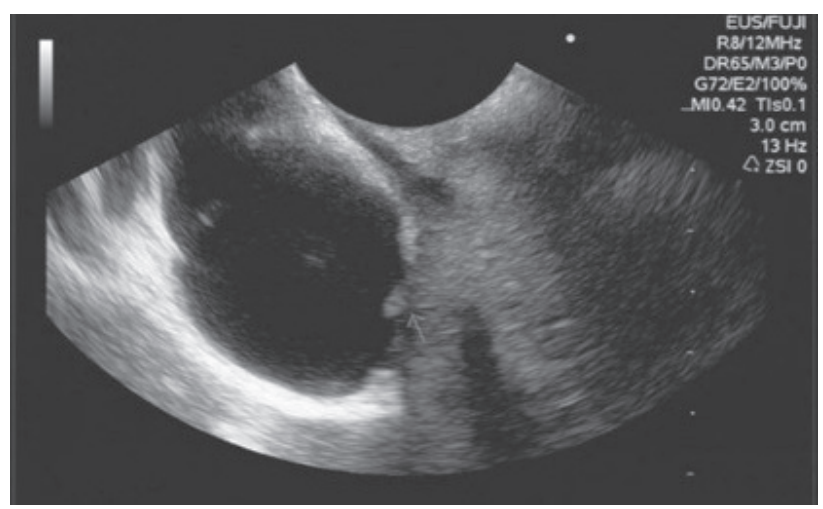

FIGURE 1 Details of the vascular invasion of the portal-splenomesenteric confluence.

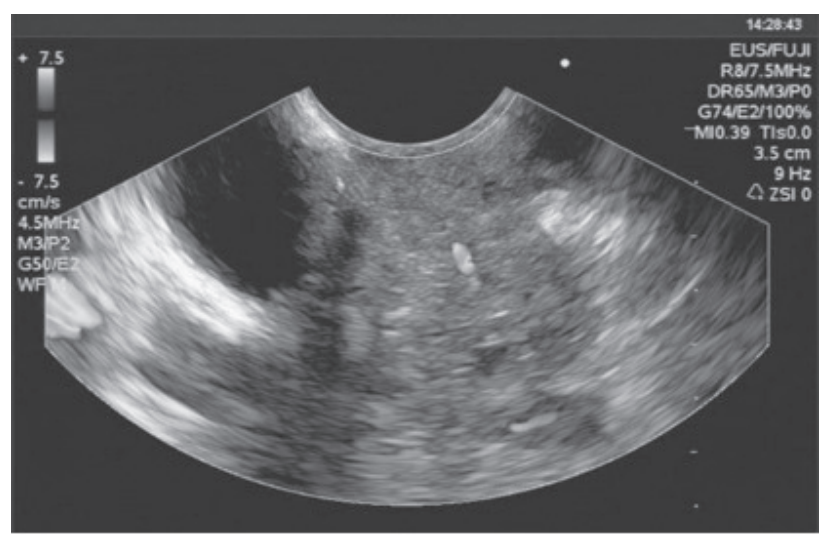

FIGURE 2 Negative Doppler suggesting portal thrombosis.

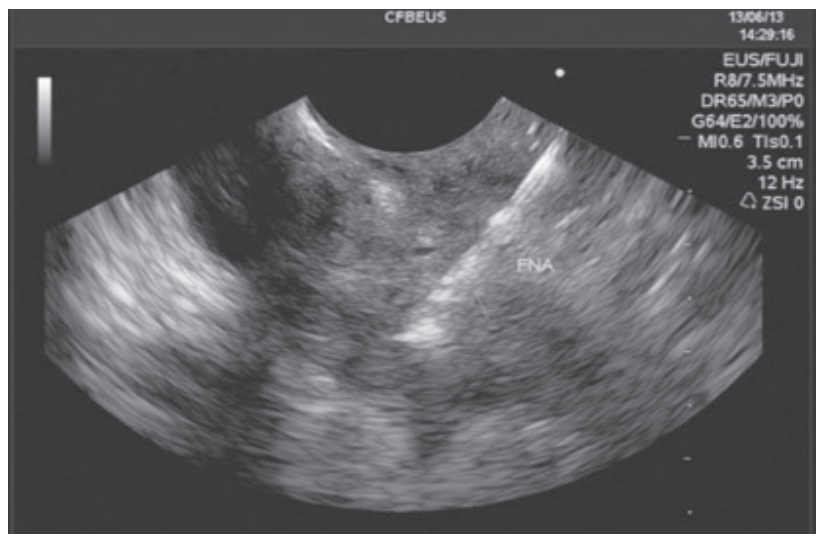

FIGURE 3 Echo-guided puncture to obtain sample material from the lesion.

\section{Discussion}

Pancreatic cancer is associated with poor prognosis. After diagnosis, the survival rate is about $3 \%$ at 5 years and only $15 \%$ of tumors are resectable. Surgical resection of the tumor is still the only curative treatment and, therefore, an accurate preoperative staging is mandatory to avoid the surgical treatment of unresectable lesions. ${ }^{1}$ 
In the absence of distant metastases, which contraindicate surgery, assessment of vascular invasion is the most important parameter to determine the resectability of the lesion. Invasion is found in 21 to $64 \%$ of cases. $^{2}$

Endoscopic ultrasound is a test that complements the evaluation made by other imaging studies (CT or $\mathrm{MRI}$ ), providing an accurate assessment of peripancreatic vasculature and the relationship between the tumor and adjacent structures. Studies have shown that the sensitivity to detect vascular invasion through endoscopic ultrasound ranges from 50 to $100 \%$, with specificity between 58 and $100 \% .{ }^{2}$ In addition to the image data, it enables the realization of intra-pancreatic and lymph node biopsies ${ }^{1,3}$ that can change the therapeutic approach. Fine needle aspiration (FNA) has a diagnostic accuracy approaching $90 \%$. Obtaining histological material from biopsy plays an important role to initiate palliative or neoadjuvant treatment. ${ }^{5}$

As to arterial blood investigation, the infiltration of large vessels such as the celiac trunk, superior mesenteric or hepatic arteries, is also a contraindication to surgical treatment. The superior mesenteric vessels are the vessels most often involved in this type of cancer, due to its close relationship with the head, uncinate process and body of the pancreas. ${ }^{2}$
In the venous study, visualization of tumor thrombus or the involvement of more than $25 \%$ of the circumference of the portal vein or superior mesenteric vein are criteria for irresectability. ${ }^{4}$

In conclusion, endoscopic ultrasound is a complementary method for staging patients with pancreatic cancer, providing data on the involvement of blood vessels and other peripancreatic structures, and allows histological definition of the lesion, which is essential for achieving adjuvanticity.

\section{References}

1. Ahmad NA, Kochman ML, Lewis JD, Kadish S, Morris JB, Rosato EF, et al. Endosonography is superior to angiography in the preoperative assessment of vascular involvement among patients with pancreatic carcinoma. J Clin Gastroenterol 2001;32(1):54-8.

2. Buchs NC, Chilcott M, Poletti PA, Buhler LH, Morel P. Vascular invasion in pancreatic cancer: imaging modalities, preoperative diagnosis and surgical management. World J Gastroenterol 2010;16(7):818-31.

3. De Angelis C, Brizzi RF, Pellicano R. Endoscopic ultrasonography for pancreatic cancer: current and future perspectivers. J Gastroenterol Oncol 2013;4(2):220-30

4. Callery MP, Chang KJ, Fishman EK, Talamonti MS, Traverso LW, Linehan DC. Pretreatment assessment of resectable and borderline resectable pancreatic cancer: expertise consensus statement. Ann Surg Oncol 2009;16(7):1727-33.

5. Garcia JI, Noia JL, Muñoz JED. Endoscopic ultrasound in the diagnosis and staging of pancreatic cancer. Rev Esp Enferm Dig 2009;101(9):631-8. 